\title{
pesquisa
}

QUEIROGA, R.C.F.; NOGUEIRA, I.C.C.; BEZERRA NETO, F.; MOURA, A.R.B.; PEDROSA, J.F. Utilização de diferentes materiais como cobertura morta do solo no cultivo de pimentão. Horticultura Brasileira, Brasília, v. 20, n. 3, p. 416-418, setembro 2002.

\section{Utilização de diferentes materiais como cobertura morta do solo no cul- tivo de pimentão}

\author{
Roberto Cleiton F. Queiroga; Isení Carlos C. Nogueira; Francisco Bezerra Neto; Antonio Roberto Brígido \\ de Moura; Josué Fernandes Pedrosa \\ ESAM, Depto. Fitotecnia, C. Postal 137, 59.625-900 Mossoró-RN; E-mail: robertocleiton@hotmail.com
}

\section{RESUMO}

Avaliou-se o efeito de diferentes tipos de cobertura morta sobre características de frutos do pimentão (Capsicum annuum L. cv. Yolo Wonder) em um experimento instalado em campo na ESAM, de junho a novembro de 1994 . O clima local é semi-árido, seco e muito quente, com as estações seca (de junho a janeiro) e chuvosa (fevereiro a maio). $\mathrm{O}$ delineamento experimental utilizado foi de blocos completos casualizados com sete tratamentos e quatro repetições. Foram utilizadas as coberturas mortas de palha de vagens de caupi, palha de carnaúba, raspa de madeira, palha de milho, palha de sorgo e palha de capim elefante e a testemunha sem cobertura. $\mathrm{O}$ diâmetro de frutos, número de frutos por planta, peso de frutos e a produção foram afetados pela cobertura morta, tendo a palha de carnaúba se mostrado superior às demais coberturas mortas. O comprimento do fruto não foi afetado pelas coberturas mortas avaliadas. A maior incidência de plantas invasoras ocorreu no tratamento com palha de vagem de caupi.
ABSTRACT

Utilization of different materials for mulching in bell pepper

The effect of different mulching materials on bell pepper (Capsicum annuum L. cv. Yolo Wonder) fruit characteristics was evaluated in an experiment carried out in Mossoró (Brasil), from June to November of 1994. The local climate is semi-arid, dry and very hot, with a dry season (June to January) followed by a rainy one (February to May). The experimental design was of randomized complete block with seven treatments and four replications. Cowpea pod straw, sliced carnauba dried leaves, wood chips, corn straw, sorghum straw and elephant-grass straw were used as mulching. The treatment using carnauba dried leaves as mulching was superior when compared to the other mulchings with regard to the diameter, fruit number and weight, and yield of fruits. The length of the fruits was not affected by treatments. Weed population was greater when cowpea pod straw was used as mulching.

Palavras-Chave: Capsicum annuum L., componentes da produção, plantas invasoras.

Keywords: Capsicum annuum L., yield components, weed.

(Recebido para publicação em 07 de dezembro de 1998 e aceito em 19 de março de 2002)

$\mathrm{O}$ pimentão (Capsicum annuum L.) figura entre as hortaliças de maior importância no Brasil, destacando-se o Sudeste como principal região produtora do país. Também, o Nordeste brasileiro apresenta ótimas condições para o cultivo dessa olerícola, notadamente o estado do Ceará, o qual apresenta-se autosuficiente na produção desta hortaliça (Muniz et al., 1987).

No Rio Grande do Norte, apesar das condições climáticas adequadas, não se alcançou, ainda, produção suficiente para evitar a importação de outros estados. Há necessidade de pesquisa com a cultura, no que diz respeito ao seu manejo, que inclui o estudo do efeito de práticas simples como o uso de cobertura morta do solo.

A cobertura morta do solo protege o mesmo das adversidades do clima. Os materiais mais utilizados são as palhas, folhas, serragens, e materiais sintéticos como o plástico, papéis e metais (Creagur \& Katchur,1975). Esta prática cultural reduz a velocidade da enxurrada, promovendo menores perdas de água e solo (Alves et al.,1995). Bragagnolo et al. (1990) afirma que a cobertura do solo reduz a perda de água por evaporação, além de diminuir as oscilações da temperatura do solo, dependendo da insolação e da umidade do solo. O seu emprego traz vantagens como alteração do regime térmico do solo, conservação da água do solo, redução da perda de nutrientes por lixiviação (Carter \& Johnson,1988), além do controle de plantas invasoras (Moura Neto,1993), além da melhoria das qualidades físicas e químicas do solo (Fialho et al., 1991).

Em Mossoró, a cobertura orgânica com palha de carnaúba triturada proporcionou aumento na produção de pimentão (Negreiros et al.,1986) e da alface (Maia Neto et al.,1987), além de con- tribuir na redução de plantas invasoras.

Este trabalho teve por objetivo verificar a influência de tipos de cobertura morta no cultivo do pimentão nas condições da microrregião salineira do Rio Grande do Norte.

\section{MATERIAL E MÉTODOS}

O experimento foi conduzido na Horta da ESAM, de junho a novembro de 1994, em solo Podzólico VermelhoAmarelo Equivalente Eutrófico. O clima é semi-árido de acordo com classificação de Thornthwaite, seco e muito quente, com duas estações climáticas: uma seca que vai de junho a janeiro e uma chuvosa que vai de fevereiro a maio.

O delineamento experimental foi de blocos casualizados completos com sete tratamentos [palha de carnaúba triturada (Copernicea cerífera Mart.), palha de milho triturada (Zea mays L.), vagem 
Tabela 1. Valores médios das matérias fresca e seca de plantas invasoras, comprimento e diâmetro do fruto, número de frutos por planta, peso de frutos e produção nos diferentes tipos de cobertura morta. Mossoró, ESAM,1994.

\begin{tabular}{|c|c|c|c|c|c|c|c|}
\hline Tratamentos & $\begin{array}{c}\text { Matéria } \\
\text { fresca de } \\
\text { plantas } \\
\text { invasoras } \\
\text { (t/ha) }\end{array}$ & $\begin{array}{c}\text { Matéria } \\
\text { seca de } \\
\text { plantas } \\
\text { invasoras } \\
\text { (t/ha) }\end{array}$ & $\begin{array}{l}\text { Comprimento } \\
\text { do fruto }(\mathrm{cm})\end{array}$ & $\begin{array}{l}\text { Diâmetro } \\
\text { do fruto } \\
\text { (cm) }\end{array}$ & $\begin{array}{l}\text { Número de } \\
\text { frutos por } \\
\text { planta }\end{array}$ & $\begin{array}{l}\text { Peso de } \\
\text { frutos (g) }\end{array}$ & $\begin{array}{l}\text { Produção } \\
\text { Total (t/ha) }\end{array}$ \\
\hline $\mathrm{RM}$ & $21,14 a b$ & $4,17 \mathrm{a}$ & $5,29 a$ & 4,88 bc & $6,55 \quad b$ & $38,1 \quad b$ & $4,18 \quad b$ \\
\hline PS & $20,98 a b$ & $4,09 a$ & $5,61 \mathrm{a}$ & $5,09 a b c$ & $8,70 \quad b$ & $43,8 \mathrm{ab}$ & $6,44 a b$ \\
\hline VF & $35,67 a b$ & $7,02 \mathrm{a}$ & $5,58 \mathrm{a}$ & $5,05 a b c$ & $8,35 \quad b$ & $41,4 \mathrm{ab}$ & $5,82 \quad b$ \\
\hline CE & $18,92 a b$ & $4,10 a$ & $5,92 \mathrm{a}$ & $5,04 a b c$ & $8,85 a b$ & $42,9 \mathrm{ab}$ & $6,43 a b$ \\
\hline PM & $12,81 a b$ & $2,74 \mathrm{a}$ & $5,56 \mathrm{a}$ & $5,19 a b$ & $10,18 a b$ & $42,6 \mathrm{ab}$ & $7,38 a b$ \\
\hline PC & $11,18 \quad b$ & $2,52 \mathrm{a}$ & $6,05 a$ & $5,29 a$ & $13,30 \mathrm{a}$ & $46,5 \mathrm{a}$ & $10,32 \mathrm{a}$ \\
\hline $\mathrm{T}$ & $37,21 \mathrm{a}$ & $7,05 \mathrm{a}$ & $5,12 \mathrm{a}$ & $4,74 \quad c$ & $6,75 \quad b$ & $36,6 \mathrm{~b}$ & $4,40 \quad b$ \\
\hline$\overline{C V}(\%) 1$ & 47,02 & 52,49 & 8,61 & 3,13 & 21,43 & 7,60 & 25,96 \\
\hline NS1 & $3,73^{* *}$ & $2,39 \mathrm{~ns}$ & $1,82 \mathrm{~ns}$ & $5,36^{* *}$ & $5,69^{* *}$ & $4,52^{* *}$ & $6,11^{* *}$ \\
\hline
\end{tabular}

${ }^{1 /}$ Coeficiente de variação (CV) e níveis de significância (NS)

*Médias seguidas pela mesma letra nas colunas não diferem entre sí a 5\% de probabilidade pelo teste de Tukey.

*Raspa de madeira (RM), palha de sorgo (PS), palha de vagem de caupi, (VF), palha de capim elefante (CE), palha de milho (PM), palha de carnaúba (PC) e testemunha (T)

de caupi (Vigna unguiculata (1) Walf.), palha de sorgo triturada (Sorghum bicolor (L.) Moench.),capim elefante triturado (Penninsetum purpureum Shum.), raspa de madeira e a testemunha sem cobertura morta] e quatro repetições.

A cultivar utilizada foi a Yolo Wonder, por ter uma boa produtividade e aceitação comercial. Cada parcela constou de cinco fileiras de plantas espaçadas de $1,0 \mathrm{~m} \times 0,60 \mathrm{~m}$ com dez plantas por fileira, sendo as linhas laterais consideradas bordaduras, estabelecendo-se uma área útil de $14,4 \mathrm{~m}^{2}$. A semeadura ocorreu no mês de junho, em sementeira previamente tratada com formol a $40 \%$.

Foi desnecessário aplicar-se calcário devido ao $\mathrm{pH}$ de 6,7 do solo ser adequado para o cultivo do pimentão. As covas foram adubadas com esterco de gado bem curtido, utilizando-se cerca de 33 t/ha. Devido aos altos teores de P e K no solo não foi realizada a adubação de plantio. As mudas foram transplantadas com quatro a seis folhas definitivas, 33 dias após a semeadura, e após o pegamento, as parcelas receberam a cobertura morta, que ficou com uma espessura em torno de $3 \mathrm{~cm}$. Foram realizadas três adubações de cobertura, à base de 200 e $100 \mathrm{~kg} / \mathrm{ha}$ de sulfato de amônio e cloreto de potássio a cada adu- bação, respectivamente, aos $15 ; 30$ e 45 dias após o transplantio de acordo com as recomendações do Laboratório de Solos da ESAM.

Os outros tratos culturais constaram de irrigação diária por gotejamento e controle de trips e cochonilhas por meio de pulverizações com Demeton-s-metil.

As colheitas, em número de nove, iniciaram-se aos 88 dias após a semeadura, com freqüência semanal.

Foi avaliado o peso da matéria fresca de plantas invasoras por meio da coleta de todas as plantas daninhas que apareciam nas parcelas, e o peso da matéria seca de plantas invasoras após secagem em estufa a $70^{\circ} \mathrm{C}$ até atingir peso constante. O comprimento e o diâmetro de frutos, número de frutos por planta, peso de frutos e produção total, foram também avaliados.

A técnica da análise de variância foi utilizada na avaliação dos diferentes tipos de cobertura morta nas características coletadas. O teste de Tukey foi também usado para comparar os efeitos médios nos tipos de coberturas.

\section{RESULTADOS E DISCUSSÃO}

Os pesos das matérias fresca e seca de plantas invasoras são apresentados na
Tabela 1. Verificou-se, em relação a estas características, que a cobertura com vagem de caupi, juntamente com a testemunha foram os tratamentos que apresentaram os maiores valores de peso de plantas invasoras. $\mathrm{O}$ tratamento com vagem de caupi não proporcionou uma cobertura eficiente do solo, favorecendo assim, uma maior incidência de plantas invasoras. Por outro lado, os tratamentos com palha de carnaúba e palha de milho apresentaram os menores valores, com um melhor controle de plantas invasoras. Este fato também foi observado por Maia Neto et al. (1987) em alface, Moura Neto (1993) com coentro, em que a cobertura com palha de carnaúba propiciou um controle eficiente de plantas invasoras.

Os tratamentos utilizados não interferiram no comprimento médio de frutos (Tabela 1), resultado semelhante ao obtido por Negreiros et al. (1986), quando verificaram que a cobertura morta utilizada em várias cultivares de pimentão não afetava esta característica.

O diâmetro de frutos foi afetado pelos tratamentos onde se verificou certa superioridade das coberturas de palha de carnaúba e palha de milho em relação às outras coberturas (Tabela 1). Este fato, deve-se, provavelmente, à melhor conservação da umidade do solo e me- 
nor incidência de ervas daninhas, proporcionando, desta maneira, melhor desenvolvimento dos frutos. Estes resultados concordam com aqueles de Filgueira Neto (1991) para a cultura do alho, em que o autor afirma que um solo com proteção superficial será mais equilibrado em umidade, sendo esta uma das condições básicas para o desenvolvimento das plantas.

Houve diferença no número de frutos por planta, dependendo das coberturas mortas empregadas (Tabela 1). A cobertura morta com palha de carnaúba influenciou positivamente o número de frutos por planta, além de contribuir para diminuir a incidência de plantas invasoras. Esta cobertura, provavelmente promoveu o abaixamento da temperatura do solo, diminuiu as perdas por evaporação e forneceu nutrientes às plantas, devido a sua rápida decomposição, como foi observado por Leopoldo \& Conceição (1975), o que é relevante nas condições de Mossoró.

O peso de frutos de pimentão foi afetado pelos tratamentos avaliados (Tabela 1). A maior média foi observada no tratamento com palha de carnaúba, embora não tenha diferido significativamente das coberturas com palha de milho, palha de capim, palha de sorgo e vagem de caupi. Este fato, pode ser atribuído, provavelmente, a uma maior conservação da umidade do solo, favorecendo assim, a decomposição mais rápida do material fornecendo nutrientes ao solo, e consequentemente, proporcionando um bom desenvolvimento dos frutos.

Foi observado efeito significativo das coberturas mortas na produção de frutos de pimentão, onde as coberturas mortas com palha de carnaúba e com palha de milho representaram os maiores valores (Tabela 1). Este resultado pode ser explicado pelo maior número de frutos por planta e maior peso de frutos, dados concordantes em parte, com Negreiros et al. (1986), onde o número de frutos por planta teve o efeito mais expressivo no aumento da produção. $\mathrm{O}$ efeito da cobertura morta com palha de carnaúba confirma os resultados obtidos por Filgueira Neto (1991), em alho, Maia Neto et al. (1987), em alface, quando utilizaram esta cobertura morta.

$\mathrm{O}$ tratamento com raspa de madeira apresentou valores próximos a testemunha, devido ser um material de lenta decomposição, não fornecendo, desta maneira, os nutrientes na época de maior exigência pela cultura. A maioria dos autores concorda que coberturas orgânicas com relação $\mathrm{C} / \mathrm{N}$ maior que $30: 1$ (Robinson, 1988) causam deficiência de $\mathrm{N}$ no solo. Este autor adverte que a imobilização é temporária e ocorre durante a decomposição do material orgânico.

O tratamento com palha de carnaúba é o mais adequado para a região, pois além de se obter os melhores resultados, existe em abundância na região. A utilização destes materiais como cobertura do solo vai depender da disponibilidade em cada propriedade, procurando desta forma, minimizar os custos.

\section{LITERATURA CITADA}

ALVES, A.G.C.; COGO, N.P.; LEVIEN, R. Relações da erosão do solo com a persistência da cobertura vegetal morta. Revista brasileira de ciência do solo, Viçosa, v. 19, n. 1, p. 127-132, 1995.
BRAGAGNOLO, N.; MIELNICZUK, J. Cobertura do solo por palha de trigo e seu relacionamento com a temperatura e umidade do solo. Revista brasileira de ciência do solo, Viçosa, v. 14, n. 3, p. 369-374, 1990

CARTER, I.; JOHNSON, C. Influence of different types of mulches on eggplant production. Hortscience, v. 23, n. 1, p. 143-145, 1988.

CREAGUR, R.A.; KATCHUR, D. An evaluation on plastic and fibrous materials as mulches for total control vegetation. Hortscience, v. 10, n. 1, p. 482, 1975.

FIALHO, J.F.; BORGES, N.F.; BARROS, N.F. Cobertura vegetal e as características químicas e físicas e atividade da microbiótica de um latossolo vermelho-amarelo distrófico. Revista brasileira de ciência do solo, Viçosa, v. 15, n. 1, p. 21-28, 1991. FILGUEIRA NETO, S.J. Efeito de seis tipos de cobertura morta em duas cultivares de alho no município de Mossoró - RN. Mossoró, ESAM, 1991. 83 p. (Coleção Mossoroense, 46, série A). LEOPOLDO, P.R.; CONCEIÇÃO, F.A. Características da cultivar Lavínia (Allium sativum L.) em função de diferentes teores de umidade do solo e cobertura morta. Revista de Olericultura, Botucatu, v. 15, n. 1, p. 44-46, 1975.

MAIA NETO, I.M.; NEGREIROS, M.Z.; NOGUEIRA, I.C.C.; PEDROSA, J.F. Efeito da cobertura morta sobre o comportamento da alface na microrregião salineira do RN. Horticultura Brasileira, Brasília, v. 5, n. 1, p. 42, 1987 (resumo).

MOURA NETO, E.L. Efeito da cobertura morta sobre a produção de quatro cultivares de coentro no município de Mossoró - RN. 1993.p. 27. (Monografia graduação).

MUNIZ, I.O.L.; SILVA, L.A.; GOMES, A.N.D.A Olericultura no Estado do Ceará. Fortaleza, EPACE/EMATERCE, 1987. 17 p. (Mimeografado)

NEGREIROS, M.Z.; NOGUEIRA, I.C.C.; PEDROSA, J.F.; LIMA e SILVA, P.S. Efeito da cobertura morta sobre o comportamento de cultivares de pimentão na microrregião salineira do Rio Grande do Norte. Horticultura Brasileira, Brasília, v. 4, n. 1, p. 44-76,1986. (resumo) ROBINSON, D.W. Mulches ornamental plantings. Author's reply. Hortscience. v. 23, n. 6,1988. 